\title{
Effect of pile and heat exchanger properties on total heat extraction of an energy pile - A numerical study
}

\author{
Mithun Mandal ${ }^{1}$, and Ramakrishna Bag ${ }^{1, *}$ \\ ${ }^{1}$ Department of Civil and Environmental Engineering, Indian Institute of Technology Patna, Bihar, 801103, India
}

\begin{abstract}
Geothermal energy is one of the potential energy resources to meet future energy demand keeping environmental pollution under control. This paper presents the use of geothermal energy for space heating from energy pile. An energy pile with a single $U$ tube heat exchanger of polyethylene (PE) pipe was modeled in this study. The effect of pile and heat exchanger properties on the total heat extraction was studied by the finite element analysis using COMSOL Multiphysics. The 3D model was developed and validated based on the literature reported results of an experimental thermal performance of a borehole equipped with a single and double $U$ tube heat exchanger. Tetrahedral elements were considered for simulation of a 3D model. The model of a single energy pile of certain dimensions with different soil layers was considered, each soil layers were associated with different temperature. The effect of various parameters such as the length of concrete pile, the diameter of concrete pile, the thickness of $U$ pipe, the inner diameter of $U$ pipe and velocity of fluid inside the $U$ pipe on amount of heat extraction was studied for an energy pile equipped with a single $U$ tube heat exchanger. It was observed that the most influential parameters in increasing the outlet temperature of the heat exchanger loop are the diameter of the concrete pile, the inner diameter of $U$ pipe and the velocity of fluid inside the $U$ pipe.
\end{abstract}

\section{Introduction}

Due to the rapid increase of population and improved living standards energy consumption has been increased continuously for the last couple of decades. Out of the total world energy demands, $80 \%$ energy produced from fossil fuels and the rest $20 \%$ produced from renewable energy sources [1-2]. For the large scale use of fossil fuels there is an enormous increase in greenhouse gas emission, which is responsible for global warming. For that, many countries are focusing to reduce the use of fossil fuel by increasing the utilization of renewable energy. The use of renewable energy provides up to $50 \%$ $\mathrm{CO}_{2}$ emission reduction for new buildings [3-4]. The present study provides one of the efficient technology that can be used to heat building using an energy pile. An energy pile is a pile equipped with individual or several pipe circuits in order to enable the exchange of heat with the surrounding soil. The energy pile also known as heat exchanger pile as it helps to transfer the heat in between the ground and earth surface. Brine, usually water with antifreeze agent is circulated with a certain velocity inside the PE pipe to extract or inject heat energy from the ground or into the ground. This technology is being used for space heating or cooling. During the winter session, when the ground soil temperature is higher than the surface temperature, the brine inside PE pipe extracts the heat from the soil and injects it into the surface to increase surface temperature and vice versa during the summer session.
Sivasakthivel et al. [5] performed an experimental investigation on the thermal performance of single and double $U$ tube heat exchangers by focusing on its effectiveness. The effect on ground temperatures, heat extraction and injection rate and its effects on surrounding and ground formations were studied. Cecinato and Loveridge [6] prepared some specific models of a thermal pile to find out the influence of pile, pipe and fluid properties on the outlet temperature. It was concluded that the surface area of pipe available for heat transfer is the most influential factor to increase energy efficiency. The velocity of fluid does not have a significant impact on the overall energy exchanged. Aydin and Sisman [7] analyzed the heat transfer rate for multi $U$ tube boreholes also measured the average fluid inlet and outlet temperature. Bozis et al. [8] described effects of various design parameters on the heat transfer efficiency of energy piles. Although some studies carried out in the past on the use of energy pile, further investigation is required for its better understanding and wider application.

This paper presents the use of geothermal energy for surface heating from an energy pile. In the present study, an energy pile with a single $U$ tube heat exchanger of polyethylene (PE) pipe was modeled as shown in Fig. 1. In the Figure, $T_{g}, T_{f}$ are the ground and fluid temperatures, respectively; $\mathrm{c}$ is the distance measured from the exposed concrete surface to the nearest surface of the $U$ tube. The effect of pile and heat exchanger properties on the total heat extraction by an energy pile

\footnotetext{
* Corresponding author: rkbag@iitp.ac.in
} 
was studied by the finite element analysis using COMSOL Multiphysics. The 3D model was developed and validated based on the results reported in the literature by Sivasakthivel et al. [5], on the experimental investigation on the thermal performance of a borehole equipped with single and double $U$ tube heat exchangers. A parametric study was carried out after model validation.

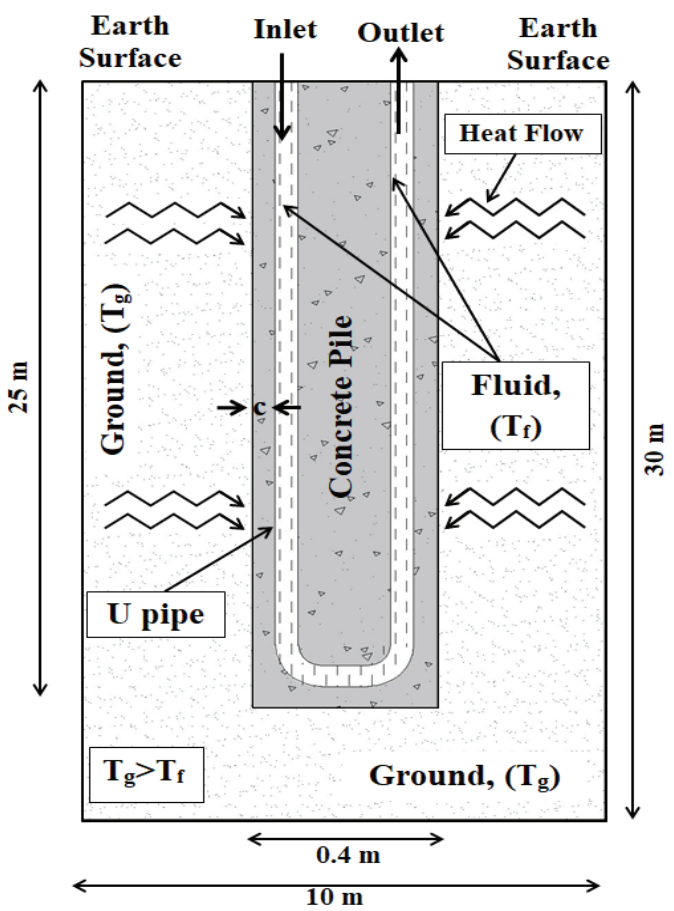

Fig. 1: Schematric diagram of an energy pile with single heat exchanger U pipe (In Winter/Heating Mode).

\section{Model preparation}

The numerical modelling was carried out using COMSOL Multi-physics software. COMSOL is a 3Dimensional finite element based software. For the parametric study a soil domain of $10 \mathrm{~m} \times 10 \mathrm{~m} \times 30 \mathrm{~m}$ was considered to ensure that there is no boundary effect on the simulation. Ten different soil layers of thickness of $3.0 \mathrm{~m}$ was considered (shown in Fig. 2). Inside the soil domain a concrete pile of diameter (D) $0.4 \mathrm{~m}$ and length (L) $25 \mathrm{~m}$ was considered. A single $\mathrm{U}$ pipe of Polyethylene (PE) was built inside the concrete pile considering clear cover (c) of $25 \mathrm{~mm}$. Both the openings of the $U$ pipe at the pile top were named as inlet and outlet openings. The properties of each soil layers were considered the same, however the temperature of each soil layers were increased with increasing the depth from the ground surface as shown in Fig. 2. As the temperature of the earth is increasing towards its center from the earth surface [9]. The material properties of soil and concrete were considered from Ferrantelli et al. [10]. Properties of other materials were considered from various literatures [11-16]. The properties of the materials are shown in Table 1.
Heat transfer in porous medium model was selected for simulation of soil, concrete and PE pipe. Laminar flow physics was considered for brine (fluid), transfer inside the PE pipe. The initial temperature of different soil layers was assigned from $290 \mathrm{~K}$ to $308 \mathrm{~K}$, respectively are shown in Fig. 2 and the initial temperature of the fluid was considered the same as surface temperature. The dynamic viscosity of water was assumed as $1.002 \times 10^{-3}$ Pa.s. Due to the pressure difference between the inlet and outlet openings, fluid flows with a certain velocity. The velocity of the fluid depends on the pressure difference between the inlet and outlet openings. With increasing the pressure difference between the inlet and outlet openings of the U pipe, the velocity of the fluid is increased. During mesh generation, tetrahedral elements were created and simulation was carried out for 365 days.

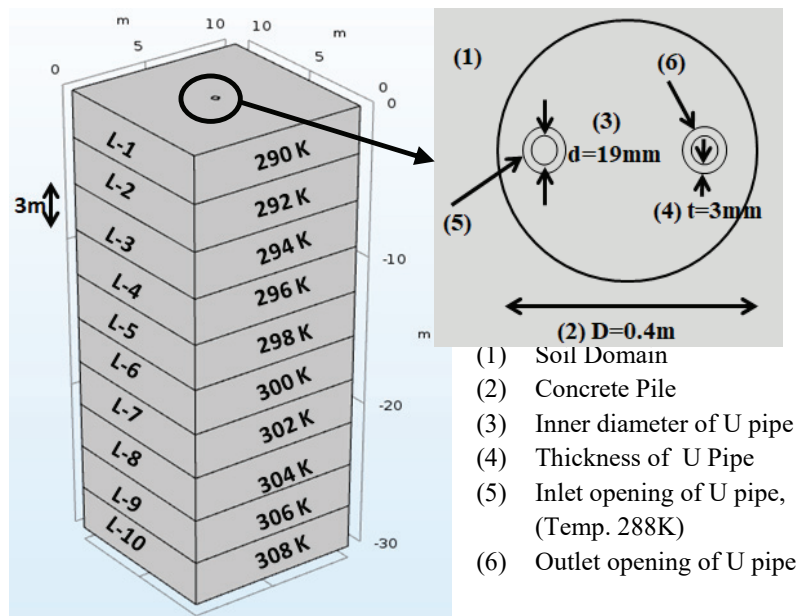

Fig. 2: A 3D model of an energy pile with all components.

Table 1: Material properties used for parametric study.

\begin{tabular}{|c|c|c|c|c|}
\hline Material & Soil & Concrete & $\begin{array}{c}\text { PE } \\
\text { tube }\end{array}$ & $\begin{array}{c}\text { Salt } \\
\text { Water }\end{array}$ \\
\hline $\begin{array}{c}\text { Thermal } \\
\text { Conductivity, } \mathrm{k} \\
(\mathrm{W} /(\mathrm{m} . \mathrm{K}))\end{array}$ & 1.25 & 1.8 & 0.5 & 0.614 \\
\hline $\begin{array}{c}\text { Specific Heat } \\
\text { Capacity, } \mathrm{C}_{\mathrm{p}} \\
(\mathrm{J} /(\mathrm{kg} . \mathrm{K}))\end{array}$ & 1710 & 880 & 1900 & 4200 \\
\hline \begin{tabular}{c} 
Density, $\rho\left(\mathrm{kg} / \mathrm{m}^{3}\right)$ \\
\hline
\end{tabular} & 1800 & 2500 & 950 & 1000 \\
\hline
\end{tabular}

\section{Validation of a 3-D model with the ex- perimental study}

The 3D model was validated by comparing the numerical results with the experimental thermal performance of ground heat exchangers reported by Sivasakthivel et al. [5]. Sivasakthivel et al. [5] performed an on field investigation of a borehole heat exchanger (BHX) in the BRGM campus, Orleans, France. The test set up was $50.0 \mathrm{~m}$ long single and double U-tube heat exchanger installed in a $180 \mathrm{~mm}$ diameter borehole, and 
was filled with grout. The thickness and external diameter of the $U$ tubes were $3 \mathrm{~mm}$ and $32 \mathrm{~mm}$, respectively. In order to circulate water into the heat exchanger a $750 \mathrm{~L}$ water tank was installed. Normal tap water was used for experiments and to avoid the freezing of water anti-freezer solution was mixed. During heating mode fluid was circulated inside the heat exchanger at the rate of $0.6 \mathrm{~m}^{3} / \mathrm{hr}$ or $0.312 \mathrm{~m} / \mathrm{s}$. In order to measure the ground temperature in different modes of operation 'pt100' temperature sensors were installed at different depths and near the borehole heat exchangers. During the experiments, both inlet and outlet temperature of the $\mathrm{U}$ pipe and fluid flowrates were monitored for a period of 8 hours. A constant ground temperature of $15^{\circ} \mathrm{C}$ and the thermal properties of the soil were assumed uniform throughout the depth of the ground.

Table 2: Material properties used for each domains in the validation problem (data from Sivasakthivel et al. [5]).

\begin{tabular}{|c|c|c|c|c|}
\hline Material & Soil & Grout & $\begin{array}{c}\text { PE } \\
\text { tube }\end{array}$ & $\begin{array}{c}\text { Salt } \\
\text { Water }\end{array}$ \\
\hline $\begin{array}{c}\text { Thermal } \\
\text { Conductivity, } \mathrm{k} \\
(\mathrm{W} /(\mathrm{m} . \mathrm{K}))\end{array}$ & 2 & 2 & 0.5 & 0.614 \\
\hline $\begin{array}{c}\text { Specific Heat } \\
\text { Capacity, } \mathrm{C}_{\mathrm{p}} \\
(\mathrm{J} /(\mathrm{kg} . \mathrm{K}))\end{array}$ & 1150 & 1150 & 1900 & 4200 \\
\hline Density, $\rho\left(\mathrm{kg} / \mathrm{m}^{3}\right)$ & 1800 & 2200 & 950 & 1000 \\
\hline
\end{tabular}

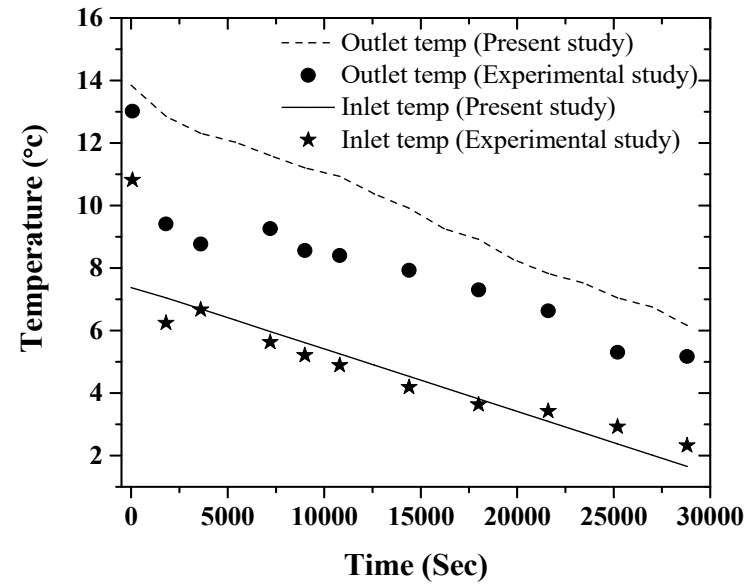

Fig. 3: Model validation with experimental study (Sivasakthivel et al. [5]).

In the present study, the experimental investigation performed by Sivasakthivel et al. [5] was validated using a 3D finite element model in COMSOL Multiphysics software. For numerical analysis a soil domain of $2 \mathrm{~m} \times 2 \mathrm{~m} \times 55 \mathrm{~m}$ was selected. Soil boundary was considered far away from the borehole to ensure that there is no effect of boundary on the simulation results. A $50 \mathrm{~m}$ long borehole with a diameter $180 \mathrm{~mm}$ was built at the center of the soil domain and filled with grout properties. A heat exchanger $U$ pipe with external diameter and thickness of $32 \mathrm{~mm}$ and $3 \mathrm{~mm}$, respectively were inserted inside the borehole by maintaining a clear cover of $25 \mathrm{~mm}$. After preparation of the whole geometry respective domain was assigned by the respective material properties. The material properties, which were used in all the domains were taken from Sivasakthivel et al. [5] are presented in Table 2. Some of the properties were considered from other literature (Ferrantelli et al. [10]). The constant ground temperature of $15^{\circ} \mathrm{C}$ was considered during the model simulation. The laminar flow of the fluid with a velocity of $0.312 \mathrm{~m} / \mathrm{s}$ was considered during the simulation of the 3D model. After the simulation, the inlet and outlet temperature of the $U$ pipe $\mathrm{w}$ ere compared with the experimental data given in the literature by Sivasakthivel et al. [5]. Fig. 3 shows that the numerical results flow similar trends with the experimental data. The small difference in the results may be attributed due to the assumption of some parameters, which were not provided in the literature by Sivasakthivel et al. [5].

\section{Results and Discussions}

After validation of the 3D model with the experimental results, a series of parametric studies were carried out on a concrete pile of diameter $0.4 \mathrm{~m}$ and length $25 \mathrm{~m}$. A heat exchanger $U$ pipe of outside diameter $25 \mathrm{~mm}$ and thickness $3 \mathrm{~mm}$ were inserted inside the concrete pile by maintaining a clear cover of $25 \mathrm{~mm}$. To find out the most effective parameter to increase the surface temperature as well as the outlet temperature of a heat exchanger $U$ pipe, a series of simulations were carried out by varying parameters. The model simulation was carried out for 365 days. The inlet temperature of the $U$ pipe was considered $288 \mathrm{~K}$ or $15^{\circ} \mathrm{C}$ and the outlet temperature was noted after the simulation. When fluid flows with a certain temperature along the pipe, it exchanges the heat with the ground as there is a temperature difference between fluid and surrounding soil. If the fluid temperature is less than the ground temperature, then the heat transferred from the ground to the fluid and therefore the fluid temperature is increased. Whereas if the fluid temperature is more than the ground temperature then heat transferred from the fluid to the ground and therefore the fluid temperature is decreased. The temperature of the fluid was noted to change with increasing the length of the pipe. For the cumulative effect of both the phenomena, outlet temperature was found to differ from the inlet temperature of the U pipe. As a results surface temperature or outlet temperature of the U pipe was noted to increase or decrease.

\subsection{Effect of inner diameter of $U$ pipe}

To find out the effect of inner diameter (d) of the U pipe in increasing the outlet temperature, several model simulations were conducted for different diameters (d). Fig. 4 shows that with increasing the value of (d) from $12 \mathrm{~mm}$ to $25 \mathrm{~mm}$, the outlet temperature is increased by $4.5 \mathrm{~K}$, when the diameter was more than $25 \mathrm{~mm}$ the outlet temperature was noted to decrease for a constant pressure difference $100 \mathrm{~Pa}$ between the inlet and outlet 
openings. One parameter of an energy pile was varied keeping all other parameters constant. According to Poiseuille's law i.e., eq. [1], the fluid flow rate was increased with increasing the diameter of the $U$ pipe for a constant pressure difference as per eq. [1]. Therefore, for the higher value of (d), fluid velocity was maximum.

$$
Q=\frac{\pi R^{4} \Delta P}{8 n L}
$$

where, $\mathrm{Q}$ is the volumetric flow rate, $\mathrm{R}$ is the pipe radius, $\Delta \mathrm{P}$ is the pressure difference between the two ends, $\mathrm{n}$ is the dynamic viscosity of the fluid and $\mathrm{L}$ is the length of the pipe.

Due to the high velocity of the fluid there was lesser time to inject the heat into the ground, when the fluid temperature was greater than the ground temperature. As a result, the outlet temperature of the $U$ pipe is increased. For diameter greater than $25 \mathrm{~mm}$ due to the higher value of (d), fluid velocity was found to be maximum. For that there was very less time to extract the heat from the ground when the fluid temperature is less than the ground temperature. As a result, the outlet temperature of the $U$ pipe is decreased.

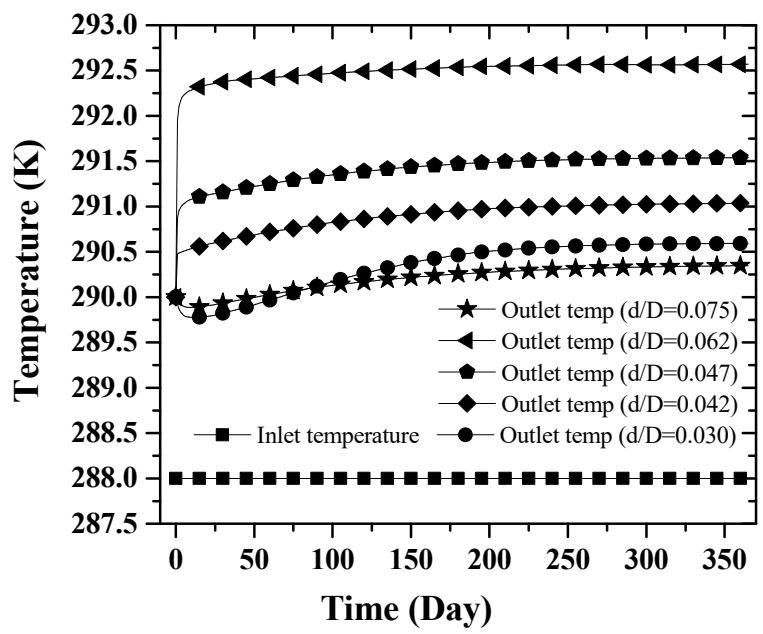

Fig. 4: Effect of the inner diameter of the U pipe in increasing the outlet temperature.

\subsection{Effect of diameter of the concrete pile}

To find out the effect of the diameter of the concrete pile in increasing the outlet temperature several model simulations were carried out for different pile diameters (D). In this case similar trends of results were observed with the effect of the inside diameter of $U$ pipe. Fig. 5 shows that with increasing the value of (D) from $0.2 \mathrm{~m}$ to $1.0 \mathrm{~m}$, the outlet temperature of the U pipe is increased by $4.25 \mathrm{~K}$. When the $\mathrm{D}$ was more than $1.0 \mathrm{~m}$ the outlet temperature was observed to decrease for a constant pressure difference of $100 \mathrm{~Pa}$ between the inlet and outlet. As the cross sectional area and the pressure difference between the inlet and outlet opening of $U$ pipe is constant, therefore the velocity of the fluid was constant. For increasing the diameter of the concrete pile up to $1.0 \mathrm{~m}$, the length of the lower portion of the $U$ pipe (i.e. horizontal part of U pipe) is increased. Therefore, the time taken by the fluid to cover this length was increased by increasing the value of (D). As the ground temperature at the lower portion of the $U$ pipe is more than the upper portion of the pipe, hence it extracts more heat from the ground. Therefore, the outlet temperature of the U pipe is increased. For the diameter (D) greater than $1.0 \mathrm{~m}$, the temperature of the fluid was observed to be higher than the ground temperature, so that heat transferred took place from fluid to ground. Therefore, the outlet temperature of the U pipe is decreased.

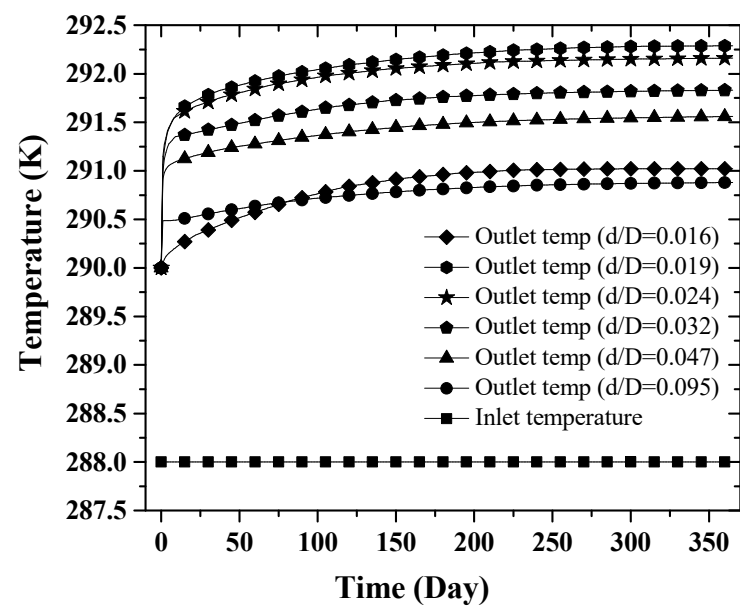

Fig. 5: Effect of the diameter of the concrete pile in increasing the outlet temperature.

\subsection{Effect of fluid velocity}

To find out the effect of fluid velocity in increasing the outlet temperature several model simulations were carried out for different values of the pressure difference between the inlet and outlet openings of $U$ pipe. Fig. 6 and Fig. 7 show that with increasing the pressure difference between the inlet and outlet openings from $50 \mathrm{~Pa}$ to $300 \mathrm{~Pa}$ outlet temperature of the $\mathrm{U}$ pipe is increased by $4.5 \mathrm{~K}$. The velocity of the fluid is increased by increasing the pressure difference between the inlet and outlet. Due to the higher velocity of the fluid, there is less time to decrease the fluid temperature when fluid temperature is more than the ground temperature. As a result, the outlet temperature of the $U$ pipe is increased. Fig. 7 also shows that with increasing the pressure difference from $50 \mathrm{~Pa}$ to $300 \mathrm{~Pa}$ velocity of the fluid, is increased from $0.010 \mathrm{~m} / \mathrm{s}$ to $0.025 \mathrm{~m} / \mathrm{s}$.

\subsection{Effect of length of the energy pile}

Fig. 8 shows that with increasing the length of the pile (L) from $15 \mathrm{~m}$ to $25 \mathrm{~m}$, the outlet temperature of the $\mathrm{U}$ pipe does not change significantly. In both cases, the results were noted to be similar for pressure difference $(\Delta \mathrm{P})$ at $100 \mathrm{~Pa}$. 


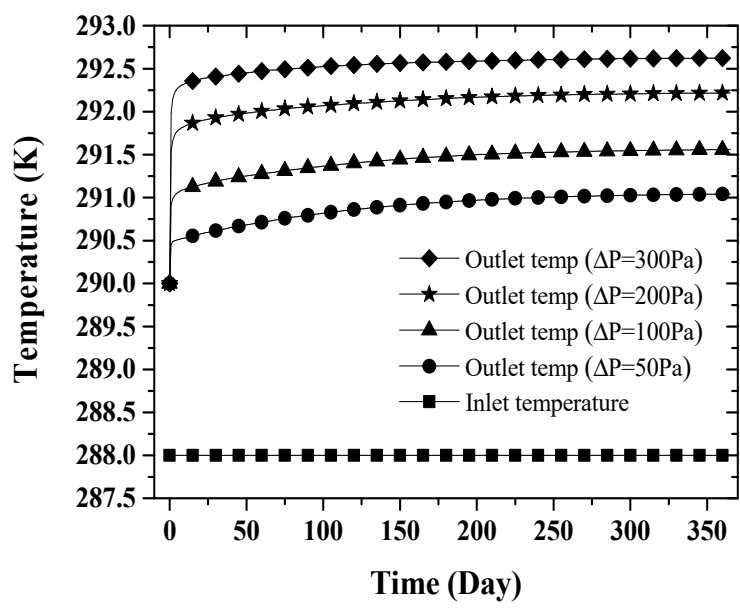

Fig. 6: Effect of pressure difference in increasing the outlet temperature.

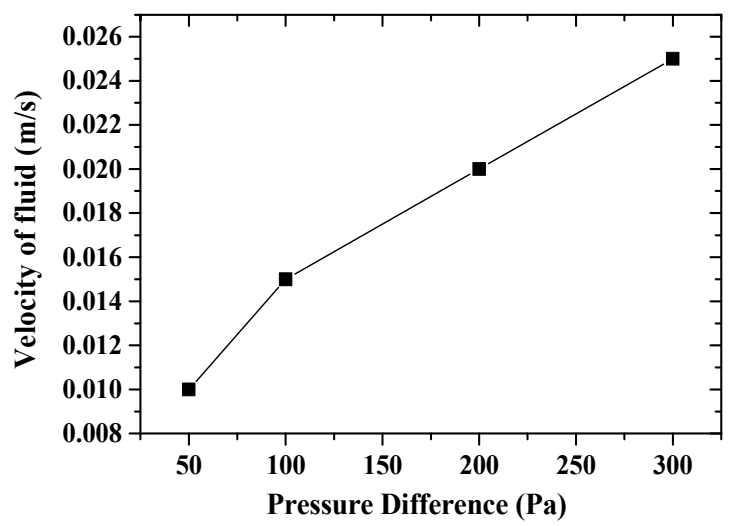

Fig. 7: Effect of fluid velocity in increasing the outlet temperature.

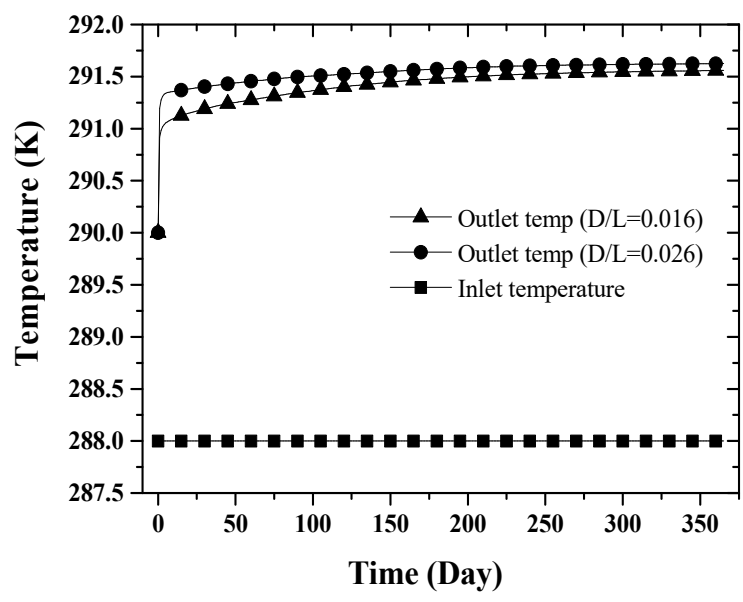

Fig. 8: Effect of length of an energy pile in increasing the outlet temperature.

\subsection{Effect of thickness of the U pipe}

To find out the effect of thickness of the $U$ pipe in increasing the outlet temperature of the $U$ pipe several model simulations were conducted for different values of thickness ( $\mathrm{t}$ ) of the $\mathrm{U}$ pipe with a pressure difference of $100 \mathrm{~Pa}$ between the inlet and outlet openings of the $\mathrm{U}$ pipe. Fig. 9 shows that with increasing the thickness of the $U$ pipe from $3 \mathrm{~mm}$ to $10 \mathrm{~mm}$, outlet temperature does not change significantly. For all the cases, it shows similar results. With an increasing the time of simulation, the outlet temperature of the $U$ pipe is increasing because the ground temperature is higher than the fluid temperature therefore continuous heat transfer from the ground to the fluid takes place.

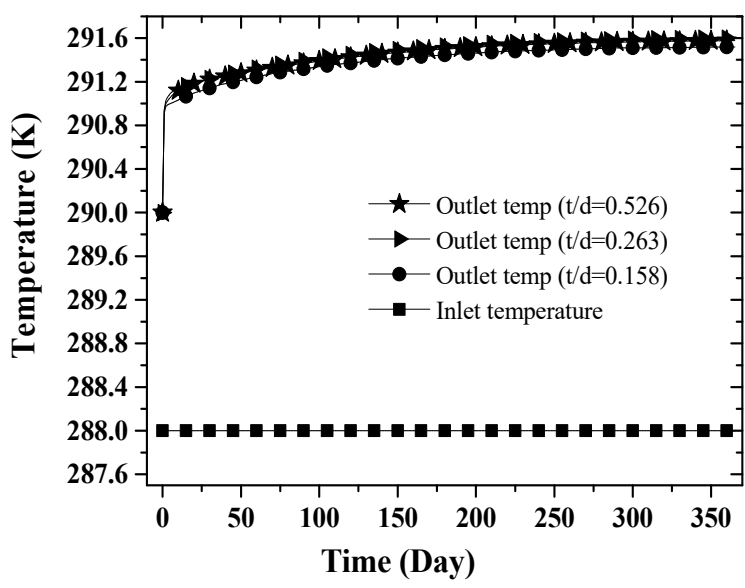

Fig. 9: Effect of thickness of U pipe in increasing the outlet temperature.

\section{Conclusions}

From the numerical analysis of an energy pile equipped with a single heat exchanger $U$ pipe following conclusions are obtained.

This study provides the use of geothermal energy in increasing the surface temperature in terms of outlet temperature of the $U$ pipe. From the parametric study, it was observed that the most influential parameter in increasing the outlet temperature is the inner diameter of the $U$ pipe and the diameter of the energy pile. It is also noted that with increase the velocity of the fluid outlet temperature is also increased.

The length of the pile and the thickness of the U pipe do not have a significant effect on the outlet temperature of the heat exchanger.

The authors are thankful to Indian Institute of Technology Patna for providing compatible laboratory and continuous support to carry out this research.

\section{References}

1. M. Kharseh, L. Altorkmany, How global warming and building envelope will change buildings energy use in central Europe, Appl. Energy, 97, 999-1004, (2012).

2. M. Kharseh, L. Altorkmany, M. Al-Khawaja, F. Hassani, Analysis of the effect of global climate change on ground source heat pump systems in 
different climate categories, Renew. Energy, 78, 219-225, (2015).

3. L. Laloui, M. Nuth, L. Vulliet, Experimental and numerical investigations of the behaviour of a heat exchanger pile, Int. J. Numer. Anal. Meth. Geomech., 30, 763-781, (2006).

4. C. Cekerevac, L. Laloui, Experimental study of the thermal effects on the mechanical behaviour of a clay, Int. J. Numer. Anal. Meth. Geomech., 28, 209228, (2004).

5. T. Sivasakthivel, M. Philippe, K. Murugesan, V. Verma, P. Hu, Experimental thermal performance analysis of ground heat exchangers for space heating and cooling applications, Renew. Energy, 113, 1168-1181, (2017)

6. F. Cecinato, F. A. Loveridge, Influences on the thermal efficiency of energy piles, Energy, 82, 1021-1033, (2015).

7. M. Aydin, A. Sisman, Experimental and computational investigation of multi U-tube boreholes, Appl. Energy, 145, 163-171, (2015).

8. D. Bozis, K. Papakostas, N. Kyriakis, On the evaluation of design parameters effects on the heat transfer efficiency of energy piles. Energ. and Buildings, 43, 1020-1029, (2011).

9. R. Jeanloz, S. Morris, Temperature distribution in the crust and mentle, Ann. Rev. Earth Planet. Sci. 14, 377-415, (1986).

10. A. Ferrantelli, J. Fadejev, J. Kurnitski, Energy pile field simulation in large buidings: Validation of surface boundary assumptions, Energies, 12, (2019).

11. K. A. Thakare, H. G. Vishakarma, A. G, Bhave, Experimental investigation of possible use of HDPE as thermal storage material in thermal storage type soalr cookers, Int. J. Res. Eng. Technol., 4, 92-99 (2015).

12. Y. Song, Y. Yao, W. Na, Impacts of soil and pipe thermal conductivity on performance of horizontal pipe in a ground-source heat pump, ESL-IC-06-11304, ICEBO, Shenzchen, China, (2006).

13. O. Bilgin, H. Stewart, T. D. O'Rourke Thermal and Mechanical properties of polyethylene pipes, J. Mater. Civ. Eng., 19, 1043-1052, (2007).

14. G. Pinter, M. Hagger, W. Balika, R. W. Lang, Cyclic crack growth tests with CRB specimens for the evaluation of the long-term performance of $\mathrm{PE}$ pipe grades, Polym. Test., 26, 180-188, (2007).

15. A. L. Horvath, Physical Properties of Inorganic Compounds, Arnold, (1975).

16. R. H. Perry, D. ed. Green, Perry's Chemical Engineers' Handbook, 6th edn., McGraw-Hill, (1985). 